\title{
Student level II fieldwork failure: strategies for intervention.
}

\author{
Sharon A. Gutman \\ Thomas Jefferson University \\ Paula McCreedy \\ New York University \\ Prudence Heisler \\ New York University
}

\section{Follow this and additional works at: https://jdc.jefferson.edu/otfp \\ Part of the Occupational Therapy Commons \\ Let us know how access to this document benefits you}

\section{Recommended Citation}

Gutman, Sharon A.; McCreedy, Paula; and Heisler, Prudence, "Student level II fieldwork failure: strategies for intervention." (1998). Department of Occupational Therapy Faculty Papers. Paper 30.

https://jdc.jefferson.edu/otfp/30

This Article is brought to you for free and open access by the Jefferson Digital Commons. The Jefferson Digital Commons is a service of Thomas Jefferson University's Center for Teaching and Learning (CTL). The Commons is a showcase for Jefferson books and journals, peer-reviewed scholarly publications, unique historical collections from the University archives, and teaching tools. The Jefferson Digital Commons allows researchers and interested readers anywhere in the world to learn about and keep up to date with Jefferson scholarship. This article has been accepted for inclusion in Department of Occupational Therapy Faculty Papers by an authorized administrator of the Jefferson Digital Commons. For more information, please contact: JeffersonDigitalCommons@jefferson.edu. 


\section{Student Level II Fieldwork Failure: Strategies for Intervention}

\author{
Sharon A. Gutman, Paula McCreedy, \\ Prudence Heisler
}

Key Words: fieldwork, occupational therapy • professional competence

Sharon A. Gutman, MA, OTR/L, is Research Associate, Department of Occupational Therapy, Thomas Jefferson University, 130 South 9th Street, Philadelphia, Pennsylvania 19107-5233.

Paula McCreedy, MEd, OTR/L, is Clinical Assistant Professor, Department of Occupational Therapy, New York University, New York, New York.

Prudence Heisler, MA, OTR/L, is Fieldwork Coordinator, Department of Occupational Therapy, New York University, New York, New York.

This article was accepted for publication June 11, 1997.
Objective. This report describes how common student communicative and behavioral characteristics that appear to predict the existence of potential problems during Level II fieldwork were identified in order to develop and implement preventative interventions during the academic curriculum at New York University (NYU).

Record review. A record review of NYU professionallevel occupational therapy students from 1986 to 1995 was completed to identify common factors among students who performed well academically but failed clinical fieldwork. Eight communicative and behavioral characteristics were identified: (a) rigidity of thinking, (b) discomfort with the ambiguity that accompanies clinical reasoning, (c) lack of psychological insight, (d) difficulty interpreting feedback, (e) externalization of responsibility, $(f)$ difficulty learning from mistakes, $(g)$ discomfort with the physical handling of patients, and ( $h$ ) dependence on external measures for self-esteem.

Intervention. On the basis of the identified characteristics, five intervention strategies were adopted: (a) academic seminars that address professional behavior and interpersonal skills, (b) faculty feedback to students regarding problematic behaviors, (c) clinician and senior student counseling with identified students, (d) student remediation programs consisting of community service, and (e) student learning contracts based on specific behavioral objectives. These strategies were administered before Level II fieldwork to 10 students in the 1996 class who exhibited the characteristics indicative of potential fieldwork failure.

Outcome. Of the 10 students in the 1996 class, 7 passed fieldwork without further difficulty, two failed fieldwork midterm assessments but went on to achieve passing final evaluations, and one failed the final fieldwork assessment but passed an additional third fieldwork experience. The class of 1996, which was the first to receive formal intervention designed to decrease fieldwork failure, demonstrated lower fieldwork failure rates than did all other classes in the past 10 years.

$\mathrm{T}$ he present physical division between theoretically based academic and practice-based fieldwork segments of occupational therapy education creates difficulty in the early detection of students who may succeed academically but perform poorly during Level II clinical fieldwork. Studies exploring correlations between academic grades and clinical fieldwork performance in occupational therapy education have suggested that academic grades alone are not effective indicators of fieldwork success or failure (Best, 1994; Booth, 1957; Englehart, 1957; Ford, 1979; Katz \& Mosey, 1980; Lind, 1970; 
Mann \& Banasiak, 1985). Although several occuparional therapy curriculums, such as those at Temple and Rush Universities, and Committee on Education presentations at the American Occupational Therapy Association's (AOTA's) Annual Conferences, have proposed methods to identify at-risk students, there are few published sources describing the methods used during academic education to identify students likely to experience fieldwork failure.

Historically, researchers have focused on the ability of IQs and grade point averages (GPAs) to predict academic and vocational success (Wechsler, 1955, 1958), but in the 1980s, predictors of success shifted toward emotional intelligence (Cantor \& Kihlstrom, 1987; Gardner, 1983). Emotional intelligence is a set of skills that contributes to the ability to (a) accurately appraise one's own and others' emotions, (b) perceive how one's behavior affects others, (c) appropriately regulate one's emorions in accordance with environmental demands, and (d) assist others to regulate their emotions and behaviors for effective daily life functioning (Goleman, 1995; Mayer, DiPaolo, \& Salovey, 1990; Salovey \& Mayer, 1990, 1994).

The possession of emotional intelligence may influence whether occupational therapy students who succeed academically will also be able to succeed clinically. Experiential observation and research suggest that occupational therapy students who have difficulty using supervisory feedback to modify inappropriate behaviors, and who experience conflict when required to assume greater flexibility, initiation, and self-imposed structure in the clinical setting, appear to be the most likely to perform poorly during fieldwork (Best, 1994; Kramer \& Stern, 1995; Mann \& Banasiak, 1985; Sands, 1995; Swinehart \& Meyers, 1993).

Because these student characteristics tend to appear in the academic environment as unprofessional attitudes and behaviors rather than as academic failure, they do not interfere with successful academic performance. Unprofessional attitudes and behaviors may include an inability to cooperate and compromise with peers and instructors; a belief that one's needs are more important than others' needs; an excessive verbalization of complaints regarding peers, instructors, and the academic institution; and a heightened degree of anxiousness in response to the requirements of independent learning.

When exhibited in the academic setting, these behaviors may be inconsistently or sporadically addressed by faculty members. Individual instructors may feel powerless to act if problematic behaviors they observe in students do not affect the students' academic grades. Additionally, systematic, departmental guidelines designed to address specific problem behaviors may be lacking. Consequently, when these behaviors are eventually exhib- ited in the clinical setting, they could lead to potential clinical failure. The purpose of this study was to identify characteristics in student communicative and behavioral skills that may predict potential failure in clinical fieldwork in order to provide intervention during the academic curriculum.

\section{Review of Student Records}

\section{Procedure}

Records of New York University (NYU) professional-level occupational therapy students from 1986 to 1995 were reviewed by the researchers to identify the common characteristics of students who performed well academically but experienced fieldwork failure. Documents reviewed were academic course grades, American Occupational Therapy Level II Fieldwork Evaluations (AOTA, 1987), and faculty-written documentation of student professional performance. Failure was defined as a failing score on a midterm, a final fieldwork evaluation, or both.

Content analysis was used to detect and measure the frequency of themes. To perform content analysis, document texts were divided into units of meaning, or categories, using specific coding rules established for the study. Coding rules describe which set of units should be grouped under each category. Caregories were later compiled into themes derived from the grouping of coded units. Themes were constructed on the basis of the relationships that emerged between categories and units of meaning (Burns \& Grove, 1993; Clubb \& Scheuch, 1980).

Interrater reliability was established to assess the extent to which all three researchers assigned the same category to a given unit of data. Each researcher independently coded and categorized a designated document. With a point-by-point agreement ratio, the categorization of units was compared directly to discern whether researchers categorized particular units in the same way (Kazdin, 1982). A point-by-point agreement ratio of .90 was found among researchers on three independent trials of three separate pieces of documentation.

\section{Record Review Analysis}

Six hundred and eighty-two students attended NYU's professional-level occupational therapy program between 1986 and 1995. Of those 682, 67 students (7 men, 60 women) were identified as having failed fieldwork or passed after failing at midterm. The disproportionate ratio of men to women reflects the ratio of male to female students in the program. Sixty-eight percent of these students passed their fieldwork after failing at midterm; 32\% failed one fieldwork experience. Ninety-eight percent of 21 students who failed one fieldwork experience complet- 
ed and passed an additional fieldwork experience; $2 \%$ voluntarily withdrew from the curriculum program. An equal number of students performed poorly on psychosocial (34) and physical disabilicy (33) fieldwork experiences. All students had B- or above academic GPAs. A GPA of $\mathrm{C}+$ is required to maintain enrollment in the program.

The common areas of communicative and behavioral difficulty identified in this group included (a) rigidity of thinking, (b) discomfort with the ambiguity that accompanies clinical reasoning, (c) lack of psychological insight, (d) difficulty interpreting feedback, (e) externalization of responsibility, (f) difficulty learning from mistakes, (g) discomfort with the physical handling of patients, and (h) dependence on external measures for self-esteem. These communicative and behavioral difficulties are discrete categories that are intimately related to each other on several qualitative dimensions.

Rigidity of thinking is a dysfunctional cognitive strategy that precludes the ability to demonstrate flexible cognitive adaptations to changes in the environment as they occur. All 67 students who performed poorly during fieldwork demonstrated an inability to cease using strategies that did not produce desired results in order to adopt new, more functional strategies. These students also commonly displayed heightened stress in response to scheduling and supervisory changes.

Discomfort with the ambiguity that accompanies clinical reasoning and decision making occurred when students had difficulty accepting the idea that more than one clinical treatment method was appropriate for the same clinical problem. It became problematic for $98 \%$ of students to relinquish their belief in the idea of the single correct answer. Clinical supervisors reported that student frustration levels increased in response to having to master alternative solutions to a single clinical problem.

Lack of psychological insight is the inability to identify and interpret one's emotions, motivations, and personality traits. Ninety-eight percent of students displayed difficulty interpreting and understanding their own responses to demands in the environment. The inability to demonstrate an understanding of one's personality traits and strengths and weaknesses impeded an accurate appraisal of one's personal skills. Clinical supervisors reported that these students commonly overestimated or underestimated their ability to appropriately meet clinical and professional challenges.

Difficulty interpreting feedback is the inability to understand others' responses in relation to one's own behavior. Because students lacked the ability to anticipate how their behaviors would be interpreted by others, they were unable to draw connections between their actions and others' responses. Consequently, 98\% displayed little ability to modify inappropriate behaviors on the basis of feedback alone. They instead complained of receiving unfair treatment, while failing to understand how their own behaviors elicited others' reactions.

Externalization of responsibility is the displacement of accountability onto others in the environment because of an inability to assume one's own obligations and duties. Ninety-five percent of students externalized responsibility for their mistakes and deficit areas in particular. When confronted with unprofessional behaviors and inappropriate clinical decisions, they commonly externalized responsibility for their actions to the clinical supervisor, the patient, and the academic institution.

Difficulty learning from mistakes involves a lack of acceptance that one has erred and an accompanying inability to rectify errors using different approaches. Ninety-five percent of students missed opportunities to learn from mistakes because of both a refusal to assume responsibility for error and an inability to cognitively switch approaches. Even when supervisors pointed out errors, these students often repeated the same mistakes because of a perseverance and rigidity of thinking that precluded their ability to relinquish the dysfunctional approach for a functional one.

Discomfort with the physical handling of patients occurs when one is uncomfortable touching patients and, consequently, jeopardizes patient safery during transfers, mobility training, and activities of daily living. Eighty percent of students who performed poorly during fieldwork displayed discomfort with the physical handling of patients. Clinical supervisors often documented that they felt uncomfortable leaving these students alone with patients and feared that both patient and student safety would be threatened if they were left without supervision.

Dependence on external measures for self-esteem occurs when one equates internal worth with academic grades and clinical evaluations. Such persons' sense of value appears to fluctuate, rather than remain stable, in relation to external measures and comparisons. Eighty percent of students demonstrated a dependence on external measures for self-esteem. These students commonly displayed difficulty in distinguishing between criticism of academic and clinical performance and criticism of themselves.

\section{Discussion of Record Review Findings}

During the record analysis process, it became apparent that the eight discrete communicative and behavioral characteristics indicative of potential fieldwork failure did not exist on the same conceptual level. Three of the eight characteristics emerged as inherent personality traits: (a) lack of psychological insight, (b) rigidity of thinking, and 
(c) difficulty interpreting feedback in response to one's behaviors. A personality trait is an enduring pattern of inner experience that organizes social and occupational functioning (American Psychiatric Association [APA], 1994). Four characteristics emerged as behavioral styles, or consequences, of the personality traits: (a) difficulty learning from mistakes, (b) discomfort with the physical handling of patients, (c) dependence on external measures for self-esteem, and (d) discomfort with the ambiguity that accompanies clinical reasoning. A behavioral style is a consistent pattern of responses used to preserve and accommodate one's personality traits (Tomb, 1988). One characteristic-externalization of responsibilityemerged as the primary defense mechanism students used in response to environmental demands. A defense mechanism is a reality-distorting strategy adopted to justify one's behaviors and preserve one's sense of self (APA, 1994; Tomb, 1988).

The personality trait, rigidity of thinking, appeared related to a discomfort with clinical ambiguity. Students who tenaciously embraced the myth of the single correct answer became anxious when required to consider alternative solutions to the same clinical problem. The cognitive flexibility required to understand that therapists use different but equally valid approaches for similar problems appeared to be hindered by student perseverance. Consequently, students had difficulty accepting the idea that they had to choose between more than one clinical approach for any given problem. They persistently believed that supervising therapists possessed the single correct answer but refused to disclose it.

The personality trait, lack of psychological insight, appeared related to a dependence on external measures for self-esteem. Students who have difficulty recognizing personal emotions, motivations, and strengths and weaknesses may tend to possess greater uncertainty regarding reality-based perceptions of internal worth. Such internal uncertainty may cause students to depend more heavily on external measures to provide an estimate of self-value. Use of external measures to provide a sense of internal worth, however, became problematic when students confused criticism of clinical performance with criticism of themselves.

The personality traits, lack of psychological insight and difficulty interpreting feedback, appear to contribute to a discomfort with the physical handling of patients. Discomfort touching others may reflect cultural norms that prohibit physical contact outside of intimate familial relationships. However, the finding that all 53 students who displayed discomfort touching parients both lacked appropriate psychological insight and had difficulty interpreting feedback suggests that cultural factors alone can- not account for discomfort with the physical handling of patients. In such cases, a relationship may exist among lack of psychological insight, difficulty interpreting feedback, and discomfort touching others. Discomfort touching others may reflect (a) an inability to accurately appraise one's own and others' emotions and (b) difficulry assessing psychological and physical interpersonal boundaries.

Rigidity of thinking, lack of psychological insight, and difficulty interpreting feedback are personality traits that appear to prevent students from engaging in behaviors necessary to learn from mistakes. Learning from mistakes is a critical step in the development of clinical reasoning, which is essential for novice therapists to enhance clinical and professional skills (Benner, 1984). Students who displayed these three personality traits could not engage in the higher level clinical reasoning processes that require constant questioning, analysis, and reformation of one's own clinical decisions over time. Because the students lacked the ability to draw connections between their actions and environmental consequences, they continuously repeated clinical and professional errors. Even when supervisors pointed out errors, the students often repeated the same mistakes because of an inability to admit error and cognitively switch approaches.

In response to the four behavioral styles (discomfort with the ambiguity that accompanies clinical reasoning, dependence on external measures for self-esteem, discomfort with the physical handling patients, difficulty learning from mistakes) students predominantly used one defense mechanism, externalization of responsibility. It was common for students who displayed heightened anxiety in response to clinical ambiguity to attribute their discomfort to the supervisor, who students considered to be inattentive, incompetent, or withholding. Students who depended on external measures for self-esteem often interpreted supervisory critique of clinical performance as personal criticism. These students tended to regard the clinical supervisors' critique of their performance as inaccurate. Rather than accept feedback and modify errors, students frequently attempted to convince supervisors of their own misunderstanding of student actions. Consequently, the need to be acquitted and absolved by the supervisor appeared to become more important than learning from mistakes.

\section{Intervention}

\section{Procedure}

On the basis of the record review findings, intervention strategies were adopted to remediate communicative and behavioral problems identified in students who exhibited the characteristics associated with potential fieldwork failure. These strategies were applied to 10 students (3 
men, 7 women) in the class of 1996 who faculty members identified through professional development evaluations completed after each semester as having the communicative and behavioral problems the researchers identified in the record review. A professional development evaluation is an assessment of the interpersonal and behavioral skills students must develop to function as skilled health care practitioners in multiple settings and professional relationships. Such skills include dependability, responsibility, emotional maturity, psychological insight, flexibility, cooperation, initiative, honesty and integrity, and the ability to consistently use these skills in appropriate verbal and written communication. These skills develop during the professional socialization process-a progressional process in which students learn to adopt the beliefs and behaviors embedded in their particular profession's philosophical assumptions and code of ethics (Sands, 1995). All 10 students identified possessed a GPA of B or higher.

Five intervention strategies were chosen to address student communicative and behavioral problems: (a) academic seminars on professional behavior and interpersonal skills, (b) faculty feedback regarding problematic behaviors, (c) counseling with clinicians and other senior students, (d) behavior remediation programs consisting of community service, and (e) student learning contracts based on specific objectives. Fieldwork seminars were added to the curriculum to prepare all students' transition from the academic environment to the clinical setting. These seminars addressed characteristics of both clinical and academic cultures, strategies for success in clinical versus academic settings, and the professional behaviors and interpersonal skills required in each environment. The seminars were conducted in the spring and fall semesters before Level II fieldwork experience.

The students were offered feedback from faculty advisors regarding how observed problematic behaviors and attitudes would likely affect their professional clinical experiences. The feedback occurred through the professional development evaluations conducted after each semester. Actual accounts of problematic student behaviors recorded throughout the academic curriculum were used to clarify and provide support for all faculty suggestions and feedback made to students (Kramer \& Stern, 1995; Sands, 1995).

Clinicians and senior students were enlisted as mentors to increase the identified students' awareness of problematic behaviors and to facilitate the acquisition of appropriate skills. Mentoring occurred in one-on-one and group sessions that took place in clinical settings or on university grounds. Commonly, mentoring occurred weekly or biweekly over 1 to 2 months. Intervention was based on experiential learning approaches that used observation, modeling, and role playing of specific behaviors identified as problematic (Bandura, 1977).

Students whose professional development evaluations continued to indicate the existence of communicative and behavioral problems after implementation of the above interventions were required to complete a 2 -month remediation program consisting of community volunteer work in a human service-related organization before Level II fieldwork commencement. Individual remediation programs were based on objectives that were congruent with each student's specific, individualized communicative and behavioral problems. The behavioral objectives of the remediation experience were formally established in a written learning contract developed by the faculty advisor and student together. A student learning contract is a formal written agreement between faculty members and students that guides learning experiences through the establishment of specific objectives (Gaiptman \& Anthony, 1989; Kramer \& Stern, 1995; Renner, Stritter, \& Wong, 1993). Student learning contracts (a) consisted of objectives that were individualized and specific to each student, (b) possessed a time frame in which objectives must be completed, (c) indicated specific evaluation criteria, and (d) designated concrete consequences for success or failure to meet the contract's goals.

Entrance in to Level II fieldwork depended on the successful achievement of the remediation program's contractual objectives. At that time, students who completed remediation programs were required to provide a written phenomenological narrative of their experience in which they demonstrated an awareness of their communicative and behavioral problems and the progress they made toward meeting the contractual objecrives.

\section{Intervention Outcome}

After the counseling intervention, 7 of the 10 students passed their fieldwork experience without further intervention. Of the three students who required additional intervention (the remediation program of community service), two passed their fieldwork experience with the assistance of a second student learning contract after receiving failing midterm evaluations. One student completed and passed a third fieldwork experience after receiving a failing fieldwork final evaluation. Upon completion of fieldwork, the 10 students were asked to participate in a 1-hr postintervention focus group with a faculty member who did not participate in the intervention (Depoy \& Gitlin, 1994) in order to describe and compare their experience of the intervention process. Seven students agreed to participate.

The addition of fieldwork seminars to the curricu- 
lum provided the opportunity for all students in the curriculum to examine the transition from academic to clinical settings. Participants in the postintervention focus group reported that the fieldwork seminars facilitated a recognition that academic and clinical settings require different strategies fot success. This recognition enabled them to begin to question whether the strategies that were personally effective in the academic setting would produce similar success in the clinic. The seminar format also enabled the students to receive feedback from peers about communicative and behavioral problems. The students perceived feedback from peers as more influential than feedback from faculty members.

Faculty member use of documented behavioral accounts to heighten students' awareness of problemaric behaviors was initially received by students with resentment. Students expressed that they were unfairly singled out. When faculty feedback was later integrated with feedback from peers, clinicians, and senior students, it became more meaningful to these students. Three students suggested that the use of actual accounts of their own behaviors facilitated examination of behaviors with less denial. Four students reported that they initially dismissed faculty feedback but later found it meaningful when assimilated with feedback from differing and unrelated sources (i.e., peers, clinicians, senior students, community service).

The use of clinician and senior student mentors to increase student awareness of problematic behaviors and enhance appropriate skills appeared effective, particularly with students who were resistant to faculty intervention. Students reported that clinician and senior student feedback was most meaningful because they believed these persons could uniquely base their feedback in current clinical experience. The students perceived faculty feedback within the academic setting as too far removed from the clinical setring to be meaningful.

The student learning contracts used in the community services remediation program appeared to work effectively for highly defensive students who tended to resist change perhaps because the contracts contained concrete behavioral objectives that required students to confront specific problems. The three students who participated in this intervention suggested that time frames and designated consequences for contract success or failure would serve to reduce anxiety by clarifying possible outcomes.

Two of these students suggested that community work enabled them to experience direct consequences of their behaviors in real-life situations. Such direct consequences compelled them to examine how their own behaviors contributed to the environmental situations in which they were involved. One student stated that having to write a phenomenological narrative of his community service experience forced him to further confront his communicative and behavioral problems by having to articulate them in written form.

\section{Discussion of Intervention}

Approximately $10 \%$ of each class between 1986 and 1995 either failed one midterm evaluation or one fieldwork experience. Similarly, in the class of 1996, 10\% $(n=10)$ of students were identified as exhibiting the communicative and behavioral characteristics indicative of potential fieldwork failure. All 10 students in the class of 1996 received intervention before Level II fieldwork experience. The outcome was that 3 of these students failed one midterm or final fieldwork evaluation, and 7 passed fieldwork without difficulty. When compared with the $10 \%$ fieldwork failure rate of each previous NYU class from 1986 to 1995 (see Table 1), the 3\% fieldwork failure rate for the class of 1996 seems significantly lower. Therefore, it seems reasonable to suggest that the intervention received by "problem" students in the 1996 class may have accounted for the observed reduction in fieldwork failure rates. Further research is required to demonstrate the effects of intervention with several NYU classes over time. After several years of data have been generated, multiple regression can be used to more accurately discern which variables actually accounted for fieldwork successfailure rates.

NYU's intervention program was limited in that it did not adequately address student discomfort with the physical handling of patients because patient contact was not an option. In the future, intervention will be modified to enable students to become more accustomed to touching others through the opportunity for hands-on practice with senior students. Additionally, because students who used learning contracts indicated that formally written concrete objectives, time frames, and consequences of behaviors promoted the acquisition of appropriate skills, future intervention will require all at-risk students to

Table 1

Percentage of Students Who Experienced
Fieldwork Failure From 1986 to 1995 Compared
With 1996 Failure Percentage After Intervention

\begin{tabular}{lccr}
\hline & & \multicolumn{2}{c}{ Students Who Failed } \\
\cline { 2 - 4 } Academic Year & Class Size & $n$ & $\%$ \\
1996 (intervention year) & 110 & 3 & 3 \\
1995 & 85 & 9 & 11 \\
1994 & 83 & 8 & 10 \\
1993 & 79 & 7 & 9 \\
1992 & 75 & 7 & 9 \\
1991 & 74 & 7 & 10 \\
1990 & 71 & 7 & 10 \\
1989 & 66 & 7 & 11 \\
1988 & 56 & 5 & 9 \\
1987 & 48 & 5 & 10 \\
1986 & 45 & 5 & 11 \\
\hline
\end{tabular}

Note. Fieldwork failure occurred if a student failed either a midterm or final fieldwork evaluation. 
develop learning contracts before fieldwork placement.

\section{Acknowledgments}

We thank Dawn Leger, PhD, Gloria Graham, MA, OTR/L, and Margery Szczepanski, MA, OTR/L, for critical review and editing.

\section{References}

American Occupational Therapy Association. (1987). Fieldwork evaluation for the occupational therapist. Rockville, MD: Author.

American Psychiacric Association. (1994). Diagnostic and statistical manual of mental disorders (4th ed.). Washington, DC: Aurhor.

Bandura, A. (1977). Social learning theory. Englewood Cliffs, NJ: Prencice Hall.

Benner, P. (1984). From novice to expert. Menlo Park, CA: Addison-Wesley.

Best, C. E. (1994). A prediction model of performance in Level II fieldwork in physical disabilities. American Journal of Occupational Therapy, 48, 926-93I.

Booth, M. D. (1957). A study of the relationship berween certain personality factors and success in clinical training of occupational therapy students. American Joumal of Occupational Therapy, 11, 93$96,126-127$

Burns, N., \& Grove, S. (1993). The practice of nursing research: Conduct, critique, and utilization. Philadelphia: Saunders.

Cantor, N., \& Kihlstrom, J. F. (1987). Personality and social intelligence. Englewood Cliffs, NJ: Prentice Hall

Clubb, J. M., \& Scheuch, E. K. (Eds.). (1980). Historical social research: The use of historical and process-produced data. Weisberg, Germany: Klett-Corta.

Depoy, E., \& Gitlin, L. N. (1994). Introduction to research: Multiple strategies for health and human services. Sr. Louis, MO: Mosby.

Englehart, H. V. (1957). An investigation of the relationship between college grades and on-the-job performance during the clinical training of occupational therapy scudents. American Joumal of Occupational Therapy, 11,97-101.

Ford, A. L. (1979). A predicrion of internship performance. American Journal of Occupational Therapy, 33, 230-234.

Gaiprman, B., \& Anthony, A. (1989). Contracting in fieldwork education: The model of self-directed learning. Canadian Journal of Ocupational Therapy, 56, 10-14.
Gardner, H. (1983). Frames of mind. New York: Basic.

Goleman, D. (1995). Emotional intelligence. New York: Bantam.

Karz, G. M., \& Mosey, A. C. (1980). Fieldwork performance, academic grades, and preselection criteria of occupational therapy students. American Journal of Occupational Therapy, 34, 794-800.

Kazdin, A. E. (1982). Single-case research designs: Methods for clinical and applied settings. New York: Oxford University Press.

Kramer, P., \& Stern, K. (1995). Case Report--Approaches to improving student performance on fieldwork. American Journal of Occupational Therapy, 49, 156-159.

Lind, A. I. (1970). An exploratory study of predicrive factors for success in the clinical affiliation experience. American Journal of Occupational Therapy, 24, 222-226.

Mann, W. C., \& Banasiak, N. (1985). Fieldwork performance and academic grades. American Journal of Occupational Therapy, 39, 92-95.

Mayer, J. D., DiPaolo, M., \& Salovey, P. (1990). Perceiving affective content in ambiguous visual stimuli: A component of emotional incelligence. Joumal of Personality Assessment, 54, 772-778.

Renner, J. J., Stritter, F. T., \& Wong, H. D. (1993). Learning contracts in clinical education. Radiologic Technology, 64, 358-365.

Salovey, P., \& Mayer, J. D. (1990). Emorional incelligence. Imagination, Cognition, and Personality, 9, 185-211.

Salovey, P., \& Mayer, ]. D. (1994). Some final rhoughrs about personality and intelligence. In J. Sternberg \& P. Ruzgis (Eds.), Personality and intelligence (pp, 303-318). Cambridge, UK: Cambridge Universicy Press.

Sands, M. (1995). Brief or New-Readying occuparional therapy students for Level II fieldwork: Beyond academics to personal behaviors and artitudes. American Journal of Occupational Therapy, $49,150-152$.

Swinehart, S., \& Meyers, S. K. (1993). Level I fieldwork: Crearing a posicive experience. American Journal of Occupational Therapy, $47,68-73$.

Tomb, D. A. (1988). Psychiatry for the house officer. Baltimore: Williams \& Wilkins.

Wechster, D. (1955). Wechsler Adult Intelligence Scale manual. New York: Psychological Corporation.

Wechsler, D. (1958). The measurement and appraisal of adult intelligence (14th ed.). Balcimore: Williams \& Wilkins. 